\title{
Metabolic fuel selection: general integration at the whole-body level
}

\author{
BY PHILIP J. RANDLE \\ Nuffield Department of Clinical Biochemistry, University of Oxford, Radcliffe Infirmary, \\ Oxford $O X 26 H E$
}

\section{Intégration au niveau de l'organisme entier}

\begin{abstract}
RÉSUMÉ
En commémorant le $200^{\text {ème }}$ anniversaire de la mort de Lavoisier, j'aimerais évoquer aussi deux autres grands scientifiques français. Louis Pasteur qui a découvert que l'O $\mathrm{O}_{2}$ inhibe la fermentation (la glycolyse), et Claude Bernard et son concept de 'la fixité du milieu intérieur'. Les principaux composants de la sélection de substrats sont le glucose (et également le glycogène, le lactate, le pyruvate, l'alanine) et les lipides (et également les adipocytes, le triacylglycérol du muscle et circulant, et les corps cétoniques), bien que les acides aminés apportent une contribution importante et indispensable. Le glucose est essentiel pour les cellules qui sont des anaérobes obligatoires et pour certaines cellules du système nerveux central. La sélection des substrats au niveau du corps tout entier est donc une caractéristique essentielle du maintien de l'homéostasie du glucose dans le sang. En situation de manque de glucides alimentaires, l'oxydation du glucose est inhibée, sauf dans les cellules pour lesquelles il est indispensable, par l'inactivation du complexe pyruvate déshydrogénase $(E C 1.2 .4 .1,2.3 .1 .12,1.6 .4 .3 ; \mathrm{PDH})$. Ceci s'effectue par l'activation de la PDH kinase (EC 2.7.1.99) par des mécanismes à court terme qui impliquent des produits de l'oxydation de lipides et des mécanismes à plus long terme qui impliquent les acides gras et l'AMPc. Le foie bascule en mode glycogénique par induction-répression des enzymes glyconéogéniques-glycolytiques par l'AMPc. La coordination s'effectue par modification des activités de l'insuline, du glucagon, des hormones thyroïdiennes, de l'hormone de croissance, des corticostéroïdes. Dans le muscle en exercice, l'utilisation du glucose est substantiellement plus importante sur des périodes qui vont jusqu'à 1 heure ou plus, avec un basculement progressif sur les substrats lipidiques. La production de lactate est considérablement augmentée, et la production de glucose hépatique s'élève par des mécanismes à court terme basés sur la production d'AMPc. La coordination s'effectue par l'action de l'insuline, du glucagon, des catécholamines et de l'hormone de croissance. Le mécanisme impliqué dans ces deux exemples d'importance capitale servira d'exemple pour l'intégration générale au niveau du corps tout entier.
\end{abstract}

In the present overview I will attempt to address biochemical mechanisms that regulate fuel selection in tissues and their relationship to coordination which is effected through regulation of endocrine and other sensor cells which monitor circulating concentrations of fuels and adjust supply and demand. Particular emphasis is placed on longer-term 
regulation of glucose oxidation, by effects of fatty acids on reversible phosphorylation in the mitochondrial pyruvate dehydrogenase (PDH) complex $(E C$ 1.2.4.1, 2.3.1.12, 1.6.4.3) and its likely further involvement in regulating the secretion of insulin and other hormones. References are limited to reviews and some recent key papers.

\section{ENERGY STORES, ENERGY EXPENDITURE AND PLASMA SUBSTRATE CONCENTRATIONS IN MAN}

The principal fuels in man and rat are glucose (also glycogen, lactate, pyruvate and alanine) and fatty acids (also adipocyte, blood plasma and muscle triacylglycerol, and ketone bodies) although amino acids make a consistent and indispensable contribution. Glucose is essential for cells that are obligatory anaerobes and for some brain cells. In man the fuel mix on an average Western diet is approximately $50 \%$ carbohydrate (half used in brain), $33 \%$ fat and $17 \%$ protein in the fed state, changing to 12,70 and $18 \%$ respectively after overnight fast ( $80 \%$ use of protein and carbohydrate by brain) and to 0 , 95 and $5 \%$ (all brain) respectively after $40 \mathrm{~d}$ of starvation. Such studies indicate that in prolonged starvation glucose oxidation is essentially replaced completely by oxidation of lipid fuels in non-brain tissues; in the brain glucose oxidation is replaced by ketone body oxidation to approximately $90 \%$. Glucose oxidation is also decreased by a lowcarbohydrate high-fat diet. Exercise increases $\mathrm{O}_{2}$ consumption and glucose oxidation; the contribution of glucose decreases with duration of exercise $(>1 \mathrm{~h})$. These changes are effected without a fall in blood glucose below levels critical for consciousness. Major hormones known to be involved in coordination are insulin, glucagon, catecholamines, growth hormone and corticosteroids (for review, see Cahill \& Owen, 1968).

In normal man in the post-absorptive state, basal rates of glucose, lipid and protein oxidation, expressed in $\mathrm{mg} / \mathrm{kg}$ per $\mathrm{min}$, are approximately equal. Resting glucose oxidation is limited by $\mathrm{O}_{2}$ consumption and, in clamp experiments, increasing blood glucose and insulin concentrations increased glucose oxidation 3-fold, suppressed lipid oxidation almost totally, but protein oxidation was unchanged (Thiébaud et al. 1982). The greatest change was in glucose storage (glycogen synthesis) which increased from 0 to $156 \mu \mathrm{mol} / \mathrm{min}$ per $\mathrm{kg}$ with a combination of hyperglycaemia and hyperinsulinaemia. Glucose oxidation is decreased in both untreated Type 1 and Type 2 diabetes; and glucose oxidation is resistant to stimulation by insulin in Type 2 diabetes, as are lipolysis and lipid oxidation (Groop et al. 1989). Numerous studies have established that raising plasma free fatty acids (FFA) by administering intralipid plus heparin decreases glucose oxidation and overall glucose utilization. This has been shown by glucose and insulinglucose clamp and employing indirect calorimetry, limb perfusion, and positron emission tomography of cardiac and skeletal muscles (for references, see Randle et al. 1994a,b). The overall decrease was approximately $25 \%$ for utilization and $50 \%$ for oxidation.

It is salutory to examine the amplitude of circulating concentrations of different fuels with dietary variation (high-carbohydrate, high-fat, starved) or exercise. Glucose shows an amplitude of only about 3-fold; lactate, pyruvate, alanine, triacylglycerol about 10-fold; FFA about 15-fold; ketone bodies about 100 -fold. Why is there such tight control of circulating glucose concentration in man (and other animals)? The recently published results of the Diabetes Control and Complications Trial (DCCT; 1993) in the USA show unequivocally that tight control of blood glucose concentration in diabetics over a prolonged period substantially reduces the incidence of retinal, renal and 


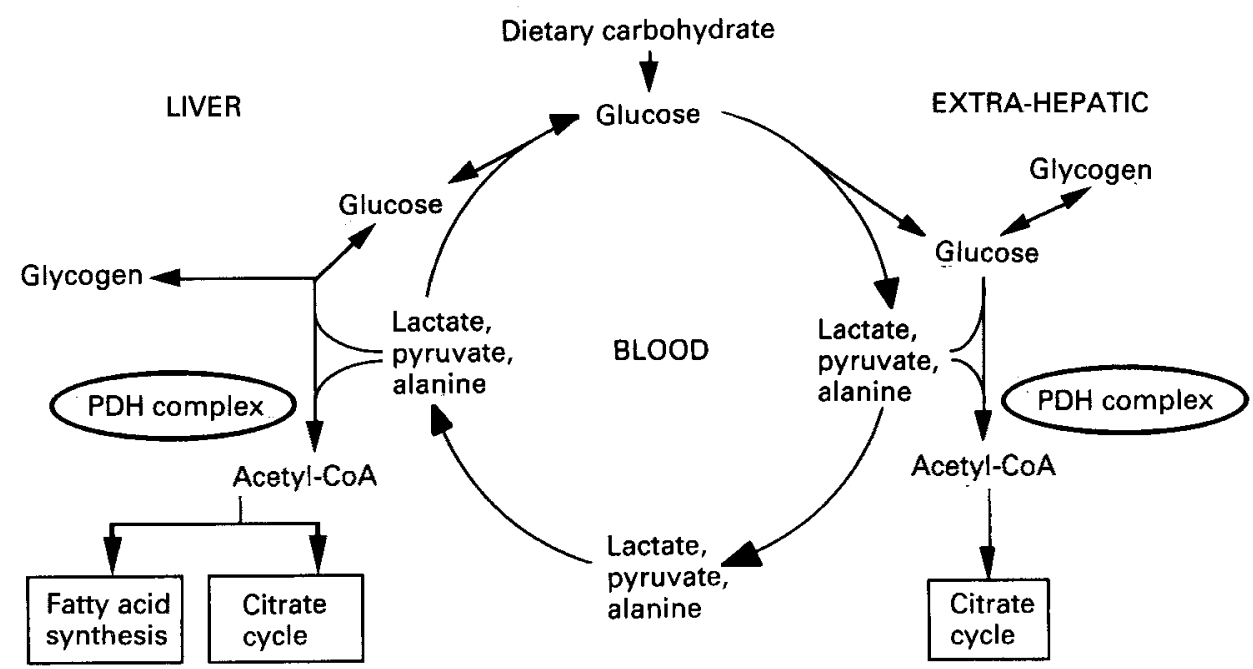

Fig. 1. The Cori cycle and other aspects of the partitioning of glucose metabolism in hepatic and extrahepatic tissues. PDH complex, pyruvate dehydrogenase complex $(E C$ 1.2.4.1, 2.3.1.12, 1.6.4.3).

neurological disorders. The molecular pathology of these disorders is not fully understood but there is a growing body of evidence that it involves non-enzymic glycation of proteins which is known to be critically dependent on circulating glucose concentration (Brownlee, 1994).

\section{REGULATED REACTIONS IN GLUCOSE DISPOSAL AND PRODUCTION}

Aspects of the partioning of tissue glucose metabolism are shown in Fig. 1; for reviews, see Granner \& Pilkis (1990) and Randle et al. $(1994 a, b)$. Glucose taken up by extrahepatic tissues (predominantly muscle) is partitioned between glycogen synthesis and glycolysis. The products of glycolysis (lactate, pyruvate and alanine) are partitioned between oxidation in mitochondria (PDH complex reaction plus citrate cycle) and release into the circulation. Except when glycogen synthesis is very rapid, glycolytic flux exceeds the rate of pyruvate oxidation and, since lactate, pyruvate and alanine are always present in the circulation, it is generally assumed that pyruvate oxidation (i.e. PDH complex activity) is rate limiting for glucose oxidation. When pyruvate oxidation is inhibited (e.g. in starvation), there is coordinated inhibition of glucose uptake and glycolysis through phosphofructokinase 1 (EC 2.7.1.11; PFK1) via citrate and ATP and of hexokinase $(E C 2.7 .1 .1 ; \mathrm{HK})$ via glucose-6-phosphate, thus limiting lactate output and glucose recycling. In general, glucose uptake is limited by the activity of glucose transporter (GLUT 4) and glycogen synthesis is in general regulated through the activities of GLUT 4 and of glycogen synthase $(E C 2.4 .1 .11)$, both of which are increased by insulin. Lactate, pyruvate and alanine released into the circulation by extrahepatic tissues are taken up by liver and either oxidized, used for fatty acid synthesis or reconverted into glucose or glycogen by the gluconeogenesis pathway. This reconversion into glucose completes the so-called Cori cycle.

In liver the disposition of lactate, pyruvate and alanine between oxidation, fatty acid 
synthesis and gluconeogenesis is determined by the relative activities of PDH complex, acetyl-CoA carboxylase (EC 6.4.1.2), and of the dicarboxylate shuttle enzymes pyruvate carboxylase $(E C$ 6.4.1.1; PC) and phosphoenolpyruvate carboxykinase $(E C$ 4.1.1.32; PEPCK). Glucose uptake in the liver is limited by the activity of glucokinase ( $E C$ 2.7.1.2; GK) which is subject to indirect endproduct inhibition by fructose-6-phosphate through a regulator protein. This inhibition is reversed by fructose- 1 -phosphate, the product of fructokinase ( $E C$ 2.7.1.4); this provides a mechanism for fructose stimulation of glucose phosphorylation and conversion to glycogen in liver. The opposing reaction in glucose production is catalysed by glucose-6-phosphatase $(E C 3.1 .3 .9)$, the regulation of which is not fully understood. Glycolytic flux and gluconeogenesis are co-regulated through three pairs of opposing reactions, i.e. (PFK1-fructose-1,6-bisphosphatase (EC 3.1.3.11)), (pyruvate kinase (EC 2.7.1.40; PK)-PC+PEPCK), and the bifunctional enzyme phosphofructokinase 2 (EC 2.7.1.105; PFK2)-fructose-2,6-bisphosphatase ( $E C$ 3.1.3.46) which generates and destroys fructose-2,6-bisphosphate, an activator of PFK1 and an inhibitor of fructose-1,6-bisphosphatase. cAMP, which mediates actions of glucagon and $\beta$-adrenergic agonists, activates gluconeogenesis and inhibits glycolysis. Through the cAMP-dependent protein kinase (A-kinase) it effects phosphorylation and inactivation of PK; switches the bifunctional enzyme to the fructose-2,6-bisphosphatase mode with concomitant inactivation of PFK2, PFK1 and activation of fructose-1,6bisphosphatase; and through effects on gene transcription lowers concentrations of GK, PFK1, PK and increases concentrations of glucose-6-phosphatase, fructose-1,6bisphosphatase and PEPCK. cAMP also lowers activities of acetyl-CoA carboxylase (through the A-kinase) and of PDH complex (discussed in detail on p. 323). Insulin has the opposite effects to those of cAMP, partly by lowering cAMP and partly by mechanisms independent of cAMP. Fatty acid oxidation enhances gluconeogenesis and inhibits glycolysis and glucose uptake through effects on the bifunctional enzyme (citrate inhibition of PFK2), PFK1 (citrate inhibition), GK, (fructose-6-phosphate inhibition) and activation of $\mathrm{PC}$.

\section{REGULATED REACTIONS IN FATTY ACID OXIDATION}

Factors regulating fatty acid oxidation have been reviewed by Brownsey \& Denton (1987) and Strålfors et al. (1987). Fatty acids for oxidation in liver and extrahepatic tissues are derived principally from plasma FFA (i.e. from adipocyte triacylglycerol by lipolysis), from muscle triacylglycerol by lipolysis, and from plasma triacylglycerol through lipoprotein lipase (EC 3.1.1.34). Lipolysis rate is determined by the activity of hormone-sensitive lipase (EC 3.1.1.3) which in adipocytes and heart muscle is activated through phosphorylation by the A-kinase. Lipolytic hormones (principally $\beta$-adrenergic agonists, also ACTH, glucagon) raise cAMP through activation of adenylate cyclase ( $E C$ 4.6.1.1). Such activation is reversed by insulin. There is presumptive evidence that skeletal-muscle hormone-sensitive lipase will be regulated by a similar mechanism. Insulin plays a key role in the regulation of adipocyte lipolysis; the administration of insulin antibodies to rats leads within minutes to an increase in plasma FFA. There is clear evidence that heart and skeletal muscle triacylglycerol furnish FFA for oxidation within the muscles.

Fatty acid oxidation is, in part, controlled by the intracellular FFA concentration which in turn is regulated by circulating FFA concentration and (in muscles) by lipolysis. 
FFA are converted to acyl-CoA in the cytosol which then give rise to mitochondrial acyl-CoA through carnitine acyltransferases I and II (EC 2.3.1.7). In liver malonyl-CoA, formed by acetyl-CoA carboxylase plays a key role in regulating fatty acid oxidation and ketone-body formation. Malonyl-CoA, which is a key intermediate in fatty acid biosynthesis, inhibits carnitine acyltransferase I and, hence, mitochondrial uptake and oxidation of fatty acyl. Acetyl-CoA carboxylase is inactivated by cAMP through phosphorylation by the A-kinase; and activated by insulin through two mechanisms. Insulin inhibits cAMP production through activation of cAMP phosphodiesterase $(E C$ 3.1.4.17) and it also induces phosphorylation of acetyl-CoA carboxylase at sites different from those phosphorylated by the A-kinase. It seems likely that acetyl-CoA carboxylase may play a role in the regulation of fatty acid oxidation in tissues such as muscle which do not synthesize fatty acids.

\section{ROLE OF THE PYRUVATE DEHYDROGENASE COMPLEX IN THE REGULATION OF GLUCOSE OXIDATION, AND IN THE SECRETION OF INSULIN AND OTHER HORMONES REGULATING BLOOD GLUCOSE CONCENTRATION}

\section{The PDH complex}

For reviews relating to PDH complex, see Randle, 1986; Reed \& Yeaman, 1987; Randle et al. 1994a,b. The PDH complex is a mitochondrial multi-enzyme complex catalysing the reaction: pyruvate $+\mathrm{CoA}+\mathrm{NAD} \rightarrow$ acetyl-CoA $+\mathrm{NADH}_{2}+\mathrm{CO}_{2}$ and generating acetyl-CoA for the citrate cycle or fatty acid synthesis. It comprises multiple copies of three component enzymes, i.e. $\mathrm{E}_{1}$ (decarboxylates pyruvate); $\mathrm{E}_{2}$ (forms acetyl-CoA) and $\mathrm{E}_{3}$ (reduces NAD to $\mathrm{NADH}_{2}$ ). As shown in Fig. 2, the PDH complex is regulated by a phosphorylation-dephosphorylation cycle. PDH complexes contain intrinsic PDH kinase (EC 2.7.1.99) which with ATPMg phosphorylates and inactivates the $E_{1}$ component. Intramitochondrial PDH phosphatase (EC 3.1.3.43), separate from the complex, catalyses dephosphorylation and reactivation. Phosphorylation is on up to three seryl residues in an $\alpha$-chain of the $\mathrm{E}_{1}$ component. Inactivation is due largely $(>90 \%)$ to phosphorylation of one serine residue (site 1); phosphorylation of the other two sites retards reactivation by PDH phosphatase. PDH kinase has been purified and contains two subunits $\alpha$ (relative molecular mass (Mr) $46 \mathrm{kDa}$, catalytic subunit) and $\beta$ (Mr $43 \mathrm{kDa}$ ). PDH phosphatase has two subunits, $\alpha$ (Mr $97 \mathrm{kDa})$ and $\beta$ (Mr $50 \mathrm{kDa}$; catalytic subunit). There is currently evidence for two isozymes of $\mathrm{PDH}$ kinase and of PDH phosphatase. Reversible phosphorylation is the major mechanism regulating the PDH complex, and glucose oxidation, in animal tissues including those of man.

\section{Shorter-term regulation by reversible phosphorylation in vivo and in vitro}

The active (dephosphorylated) and inactive (phosphorylated) forms of PDH complex are referred to as PDHa and PDHb. Except in adipose tissue of rats fed on a high-fat diet for a prolonged period, the total amount of $\mathrm{PDH}$ complex in rat tissues (PDHa $+\mathrm{PDHb}$ ) is not altered by the physiological and pathophysiological variations to be detailed.

In rat heart, skeletal muscles, liver, kidney, adipose tissue and intestine the percentage of PDHa is decreased by conditions which decrease glucose oxidation, i.e. $24-48 \mathrm{~h}$ of 


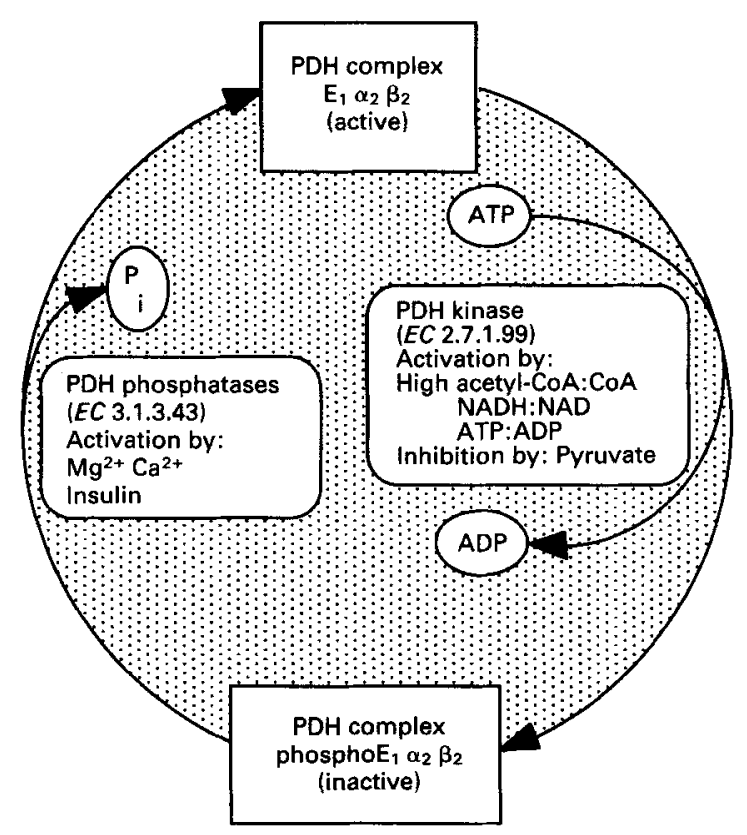

Fig. 2. Regulation of the pyruvate dehydrogenase ( $\mathrm{PDH})$ complex $(E C 1.2 .4 .1 ;, 2.3 .1 .12,1.6 .4 .3)$ by reversible phosphorylation.

starvation, or of high-fat low-carbohydrate diet or of insulin-deficient diabetes; reversal by carbohydrate refeeding or insulin treatment also requires $24-48 \mathrm{~h}$. Exercise, which increases glucose oxidation, increases the percentage of PDHa. The decrease in the percentage of PDHa due to the effects of diet or diabetes persists in isolated tissues incubated in vitro, and the increase in the percentage of PDHa due to the effects of contraction in skeletal muscles and of increased work in the heart is also demonstrable with in vitro preparations. The increase in the percentage of PDHa due to the effect of exercise is decreased in hearts of starved or diabetic rats as compared with controls. Insulin increases the percentage of PDHa in rat adipocytes by 1.8-2-fold in 5-8 min and a smaller effect (1.2-fold) has been seen in rat hepatocytes, but consistent in vitro effects of insulin in heart or skeletal muscle have not been demonstrated. Rapid effects of other hormones include increases in the percentage of PDHa induced in liver by $\alpha$-adrenergic agonists and vasopressin and in heart muscle by $\beta$-adrenergic agonists. In vitro effects of short-chain and long-chain FFA or of ketone bodies in decreasing the percentage of PDHa have been shown in perfused rat heart, perfused rat liver (FFA only) and skeletal muscles (ketone bodies only). Elevating plasma FFA has been shown to decrease the percentage of PDHa in skeletal muscles in vivo. The effects of long-chain FFA (but not of ketone bodies) are blocked by carnitine acyltransferase inhibitors such as Etomoxir and 2-tetradecylglycidate (TDG).

The major short-term effectors of PDH kinase and of PDH phosphatase are shown in Fig. 2 and their role in effects of diet and diabetes in Fig. 3. Increased mitochondrial concentration ratios for acetyl-CoA:CoA and $\mathrm{NADH}_{2}: \mathrm{NAD}$ would appear to mediate short-term effects of fatty acids and ketone bodies, and effects of diet and diabetes in decreasing PDHa, through activation of PDH kinase. The increase in PDHa in muscle 


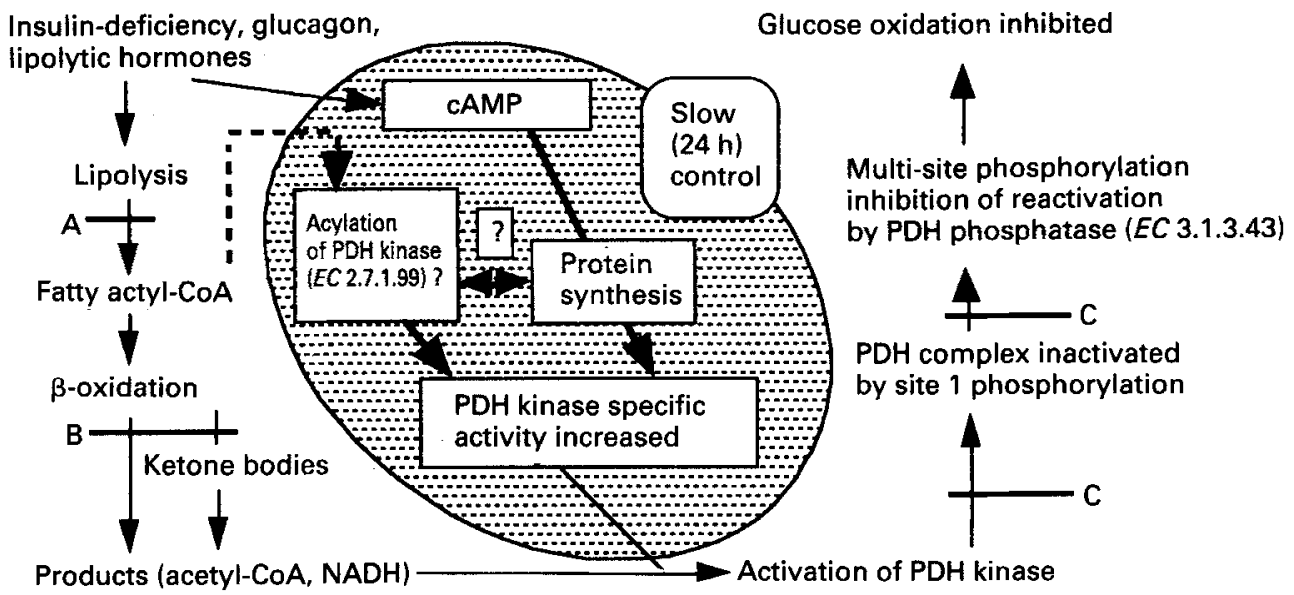

Fig. 3. Short-term (peripheral) and longer-term (国) mechanisms leading to phosphorylation and inactivation of the pyruvate dehydrogenase (PDH) complex in starvation or insulin-deficient diabetes. A, inhibitors of lipolysis, e.g. Acipimox, 5-methylpyrazole-3-carboxylic acid; B, inhibitors of carnitine acyltransferase (EC 2.3.1.7), e.g. Etomoxir, 2-tetradecylglycidate; $\mathrm{C}$, inhibitors of PDH kinase (EC 2.7.1.99), e.g. dichloroacetate.

effected by contraction is largely mediated by $\mathrm{Ca}^{2+}$ activation of $\mathrm{PDH}$ phosphatase (the increase in cytosolic $\mathrm{Ca}^{2+}$ which initiates contraction also increases mitochondrial $\mathrm{Ca}^{2+}$ ). The increases in PDHa induced in liver by $\alpha$-adrenergic agonists and vasopressin, and in heart by $\beta$-adrenergic agonists are likewise mediated by $\mathrm{Ca}^{2+}$. The action of insulin in effecting conversion of $\mathrm{PDHb}$ into $\mathrm{PDHa}$ in rat adipocytes results from activation of $\mathrm{PDH}$ phosphatase by a further unknown mechanism.

\section{Longer-term regulation of PDH kinase}

In the rat, starvation, a high-fat low-carbohydrate diet and insulin-deficient diabetes increase 2-3-fold the activity of PDH kinase in extracts of heart, skeletal muscle or liver mitochondria; the effects are reversed by carbohydrate refeeding or insulin treatment, as appropriate. This is a stable form of activation which persists through isolation of mitochondria and incubation with uncoupler to effect conversion of inactive PDH complex into active complex. It is different from the activation by acetyl-CoA and $\mathrm{NADH}_{2}$ which is readily reversed on their removal. Experiments with rat hepatocytes, cardiac myocytes and soleus muscle strips in tissue culture have identified FFA ( $n$-octanoate or albumin-bound palmitate) or agents which increase cAMP (glucagon or dibutyryl cAMP) as factors, which together with insulin deficiency, may mediate the effects of diet and diabetes. Culture of hepatocytes from starved rats reversed the effect of starvation on PDH kinase activity by about $60 \%$ in $21 \mathrm{~h}$; this reversal was blocked by $n$-octanoate, dibutyryl cAMP, glucagon, alone or in combination.

\section{Mechanism of longer-term regulation}

It was possible, in rat heart or rat liver mitochondrial extracts, to separate from PDH complex a protein fraction which enhanced the PDH kinase activity of highly purified 
pig-heart PDH complex. Purification has shown that this activity is due at least in part to the catalytic subunit of one of two PDH kinases identified in rat liver mitochondria (PDH kinase $\alpha 1$; PDHK $\alpha 1$ ). This conclusion was confirmed by purifying to apparent homogeneity and performing $\mathrm{N}$-terminal amino acid sequencing. The specific activity of purified PDHK $\alpha 1$ from starved rats was $4 \cdot 5$-fold greater than that from fed rats. Further support for this conclusion has been obtained by employing polyclonal antibodies to the purified subunit in an ELISA assay for PDHK $\alpha 1$ in mitochondrial extracts (Priestman et al. 1994). This showed no significant difference between the concentrations of this protein in extracts of liver mitochondria from fed rats and those from starved rats.

Two alternative hypotheses are consistent with these findings, i.e. that starvation increases the specific activity of KAP by covalent modification or that there are two isoforms of PDH kinase which differ in specific activity and that starvation increases the relative concentration of the more active isozyme. In studies with hepatocytes in tissue culture it was shown that the protein synthesis inhibitor cycloheximide blocked the effect of dibutyryl cAMP to increase PDH kinase activity, but not that of palmitate. Etomoxir $(1 \mathrm{~mm})$, which inhibits carnitine acyltransferase and formation of intramitochondrial fatty acyl-CoA blocked the effect of palmitate (Fig. 3) suggesting the interesting possibility that fatty acyl-CoA or a product of its $\beta$-oxidation may mediate the effect of palmitate. One possibility is fatty acylation of PDHK $\alpha 1$. Fatty acylation of cysteinyl-SH and seryl or threoninyl-OH groups in proteins is known to show turnover in vivo, i.e. there is an acylation-deacylation cycle presumably catalysed by an acyl transferase and a deacylase. With the ELISA assay it was found that dibutyryl cAMP increased the specific activity of PDH kinase in cultured hepatocytes and had no effect on the concentration of PDHK $\alpha 1$. This suggested the intriguing possibility that dibutyryl cAMP might act by inducing the synthesis of an acyltransferase. However, we do not as yet know whether the cAMP effect is blocked by Etomoxir (this would be expected if fatty acyl-CoA is involved in the effect of cAMP).

\section{Mechanisms by which starvation and diabetes decrease the activity of the pyruvate dehydrogenase complex and the rate of glucose oxidation}

The current state of knowledge of the mechanisms by which starvation or diabetes lead to phosphorylation and inactivation of the PDH complex in rat heart, skeletal muscle and liver is summarized in Fig. 3, which indicates both short-term and long-term mechanisms.

That shorter-term mechanisms based on oxidation of lipid fuels are of continuing importance in starvation and diabetes can be deduced from rapid (minutes) restoration of the percentage of PDHa to normal in rat heart muscle following in vivo and in vitro administration of the $\beta$-oxidation inhibitor TDG. TDG was not effective in skeletal muscle but the lipolysis inhibitor 5-methylpyraxole-3-carboxylic acid inhibited the decrease in the percentage of PDHa in skeletal muscles effected by starvation, whereas elevation of plasma FFA with maize oil-heparin accelerated it (Holness et al. 1989). There is some evidence to suggest that the effects of FFA in decreasing the percentage of PDHa and glucose oxidation can be inhibited by hyperinsulinaemia (for review, see Holness \& Sugden, 1990). The probable role of cAMP in mediating longer-term effects of starvation and diabetes on PDH kinase is assumed from the known increases in tissue cAMP in starved and/or diabetic rats. 


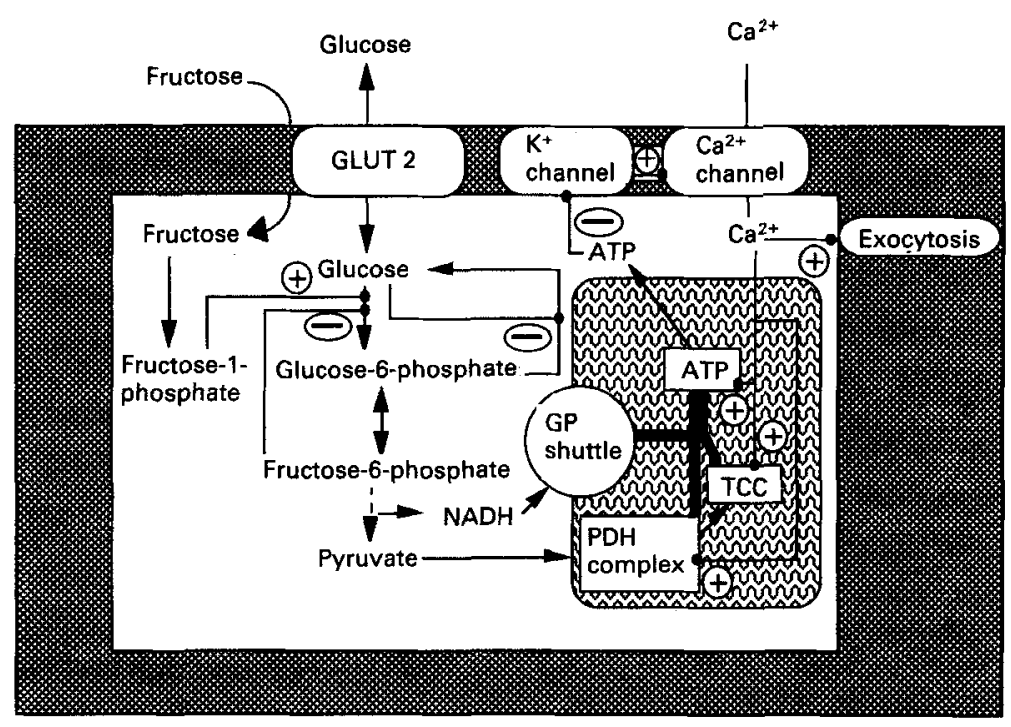

Fig. 4. Pathways mediating glucose-induced insulin secretion in the pancreatic islet $\beta$-cell. ( $\longrightarrow$ ), Regulatory effect, $(\Theta)$, activation; $(\Theta)$, inhibition; GP, glycerophosphate; TCC, citrate cycle; GLUT 2 , glucose transporter; PDH complex, pyruvate dehydrogenase complex (EC 1.2.4.1, 2.3.1.12, 1.6.4.3).

In man, starvation, Type 1 diabetes and Type 2 diabetes, and elevation of plasma FFA in normal people, decrease the utilization and oxidation of glucose and increase the oxidation of FFA, whereas inhibitors of lipolysis (5-methylpyrazole-3-carboxylic acid; Acipimox), FFA oxidation (Etomoxir, TDG) and PDH kinase (dichloroacetate) increase glucose oxidation (for references, see Randle et al. 1994b).

\section{Fatty acids and insulin secretion}

Sako \& Grill (1990) first observed in rats that in the $48 \mathrm{~h}$ period after infusion of intralipid there is impaired insulin secretory response to glucose in the isolated perfused pancreas. Studies with isolated islets indicated that this effect of intralipid was associated with decreased glucose oxidation and was inhibited by the carnitine acyltransferase inhibitor Etomoxir. More recent studies have shown that long-term exposure to palmitate in cultured rat and human islets inhibits the insulin secretory response to glucose, that the effect is inhibited by Etomoxir and provided evidence that the fatty acid effect is coupled to activation of PDH kinase (Grill \& Zhou, 1994; Zhou \& Grill, $1994 a, b)$. Shorter exposure to intralipid in vivo resulted in an exaggerated insulin secretory response to glucose. There is no obvious explanation for this finding especially as high FFA inhibit glucagon secretion.

These findings relating to inhibition of glucose-induced insulin secretion by fatty acids are explicable in terms of current views concerning biochemical mechanisms involved in glucose-induced insulin secretion. These are summarized in Fig. 4. Hyperglycaemia increases glucose metabolism in islet $\beta$-cells by increasing flux through GLUT 2 and GK (the latter is rate-limiting and functions as the islet glucoreceptor) and also by inhibition of glucose-6-phosphatase. This leads to increased glycolytic flux. Activity of lactate 
dehydrogenase ( $E C$ 1.1.1.27) in $\beta$-cells is low and there is an active glycerophosphate shuttle (Sekine et al. 1994). This may be expected to increase islet pyruvate and PDHa (pyruvate inhibits PDH kinase) resulting in enhanced flux through the PDH complex reaction and the shuttle, and increased mitochondrial and cytosolic ATP:ADP. The latter closes the ATP-sensitive $\mathrm{K}^{+}$channel and opens the voltage-dependent $\mathrm{Ca}^{2+}$ channel, resulting in increased cytosolic $\mathrm{Ca}^{2+}$ (which effects insulin secretion through exocytosis) and increased mitochondrial $\mathrm{Ca}^{2+}$ (which is expected to further increase PDHa activity through activation of $\mathrm{PDH}$ phosphatase and to increase ATP:ADP through activation of Ca-sensitive mitochondrial dehydrogenases and respiratory-chain phosphorylation; for reviews, see McCormack et al. 1990; Ashcroft \& Ashcroft, 1992; Brown, 1992; Randle, 1993). In the $\beta$-cell, PDH-complex activity is central to the generation of ATP by respiratory-chain phosphorylation in response to glucose concentration. The associated large free energy change $\left(\Delta \mathrm{G}^{\mathrm{O}^{\prime}}\right)$ of the reaction $\left(\Delta \mathrm{G}^{\mathrm{O}^{\prime}} 39 \cdot 5\right.$ $\mathrm{kJ} / \mathrm{mol}$, equilibrium constant $5.4 \times 10^{6}, \mathrm{pH} \mathrm{7}$ ) drives the oxidation of pyruvate and of cytosolic $\mathrm{NADH}_{2}$.

Finally, there is the intriguing possibility that the mechanism of glucoreceptors in the brain may be similar to that of the islet $\beta$-cell. If this is so, then long-term effects of lipid fuels on activities of PDH kinase and, hence, $\mathrm{PDH}$ complex might also be central to altered secretion of growth hormone, adrenocorticotrophic hormone and catecholamines in starvation.

\section{REFERENCES}

Ashcroft, F. M. \& Ashcroft, S. J. H. (editors) (1992). Mechanism of insulin secretion. In Insulin, pp. 97-150. Oxford: Oxford University Press.

Brown, G. C. (1992). Control of respiration and ATP synthesis in mammalian mitochondria and cells. Biochemical Journal 284, 1-13.

Brownlee, M. (1994). Glycation and diabetic complications. Diabetes 43, 836-841.

Brownsey, R. W. \& Denton, R. M. (1987). Acetyl CoA carboxylase. In The Enzymes, vol. 18, pp. 123-146 [P. D. Boyer and E. G. Krebs, editors]. London: Academic Press.

Cahill, G. F. \& Owen, O. E. (1968). Some observations on carbohydrate metabolism in man. In Carbohydrate Metabolism and its Disorders, pp. 497-523 [F. Dicken, P. J. Randle and W. J. Whelan, editors]. London and New York: Academic Press.

Diabetes Control and Complications Trial (1993). The diabetes control and complications trial. New England Journal of Medicine 329, 683-689.

Granner, D. \& Pilkis, S. (1990). The genes of hepatic glucose metabolism. Journal of Biological Chemistry 265, $10173-10176$.

Grill, V. \& Zhou, Y. P. (1994). Fatty acids and ketones inhibit $\beta$-cell function in human islets of Langerhans. Diabetologia 37, Suppl, 1, A11.

Groop, L. C., Bonadonna, R. C., Delprato, S., Ratheiser, K., Zyck, K., Ferrannini, E. \& DeFronzo, R. A. (1989). Glucose and free fatty acid metabolism in non-insulin-dependent diabetes mellitus - evidence for multiple sites of insulin resistance. Journal of Clinical Investigation 84, 205-213.

Holness, M. J., Li, Y.-L. \& Sugden, M. J. (1989). Time courses of the responses of pyruvate dehydrogenase activities to short term starvation in diaphragm and selected skeletal muscles of the rat. Biochemical Journal 265, 771-776.

Holness, M. J. \& Sugden, M. C. (1990). Glucose utilization in heart, diaphragm and skeletal muscle during the fed to starved transition. Biochemical Journal 270, 245-249.

McCormack, J. G., Halestrap, A. P. \& Denton, R. M. (1990). Role of calcium ions in regulation of mammalian intramitochondrial metabolism. Physiological Reviews 70, 391-425.

Priestman, D. A., Mistry, S. C., Halsall, A. \& Randle, P. J. (1994). Role of protein synthesis and of fatty acid metabolism in the longer-term regulation of pyruvate dehydrogenase kinase. Biochemical Journal 300, $659-664$. 
Randle, P. J. (1986). Fuel selection in animals. Nineteenth Ciba medal lecture. Biochemical Society Transactions 14, 799-806.

Randle, P. J. (1993). Glucokinase and candidate genes for Type 2 (non-insulin-dependent) diabetes mellitus. Diabetologia 36, 269-275.

Randle, P. J., Priestman, D. A., Mistry, S. C. \& Halsall, A. (1994a). Glucose fatty acid interactions and the regulation of glucose disposal. Journal of Cellular Biochemistry $\mathbf{5 5 5}, 1-11$.

Randle, P. J., Priestman, D. A., Mistry, S. C. \& Halsall, A. (1994b). Mechanisms modifying glucose oxidation in diabetes. Diabetologia 37, Suppl. 2, S155-S161.

Reed, L. J. \& Yeaman, S. J. (1987). Pyruvate dehydrogenase. In The Enzymes, vol. 18, pp. 77-95 [P. D. Boyer and E. G. Krebs, editors]. London: Academic Press.

Sako, Y. \& Grill, V. E. (1990). A 48 h lipid infusion in the rat time-dependently inhibits glucose-induced insulin secretion and $\beta$ cell oxidation through a process likely coupled to fatty acid oxidation. Endocrinology 127, 1580-1589.

Sekine, N., Cirulli, V., Regazzi, R., Brown, L. J., Gine, E., Tamarit-Rodriguez, J., Girotti, M., Marie, S., Macdonald, M. J. \& Wollheim, C. B. (1994). Low lactate dehydrogenase and high mitochondrial glycerol phosphate dehydrogenase in pancreatic beta cells. Potential role in glucose sensing. Journal of Biological Chemistry 269, 4895-4902.

Strålfors, P., Olsson, H. \& Belfrage, P. (1987). Hormone-sensitive lipase. In The Enzymes, vol. 18, pp. 147-177 [P. D. Boyer and E. G. Krebs, editors]. London: Academic Press.

Thiébaud, D., Jacot, E., DeFronzo, R. A., Maeder, E., Jéquier, E. \& Felber, J.-P. (1982). The effect of graded doses of insulin on total glucose uptake, glucose oxidation and glucose storage in man. Diabetes 31, 957-963.

Zhou, Y. P. \& Grill, V. (1994a). Evidence that fatty acids inhibit $\beta$-cell function through activation of PDH kinase. Diabetologia 37, Suppl. 1, A11.

Zhou, Y. P. \& Grill, V. (1994b). Long term exposure of rat pancreatic islets inhibits glucose-induced insulin secretion and biosynthesis through a glucose fatty acid cycle. Journal of Clinical Investigation 93, 870-876. 